\title{
THE STRUCTURE AND DISTRIBUTION OF TOURIST ACCOMMODATION BASE IN WESTERN CAUCASUS
}

The development of accommodation base, which marked the beginning of tourism in the Caucasus area, started in the mid-19th century. Until the October Revolution (1917) there were only small, private hotels and sanatoria in the area. Later on there began mass development of tourism of the recreational and therapeutic character. In 1940 in Western Caucasus there were 76 objects of accommodation base, in 1960 - in spite of wartime destructions - 154, and in 1993 - as many as 528 such objects.

The accommodation base of Western Caucasus includes seven types of objects (Table 1, Fig. 1). The most numerous group is formed by recreation

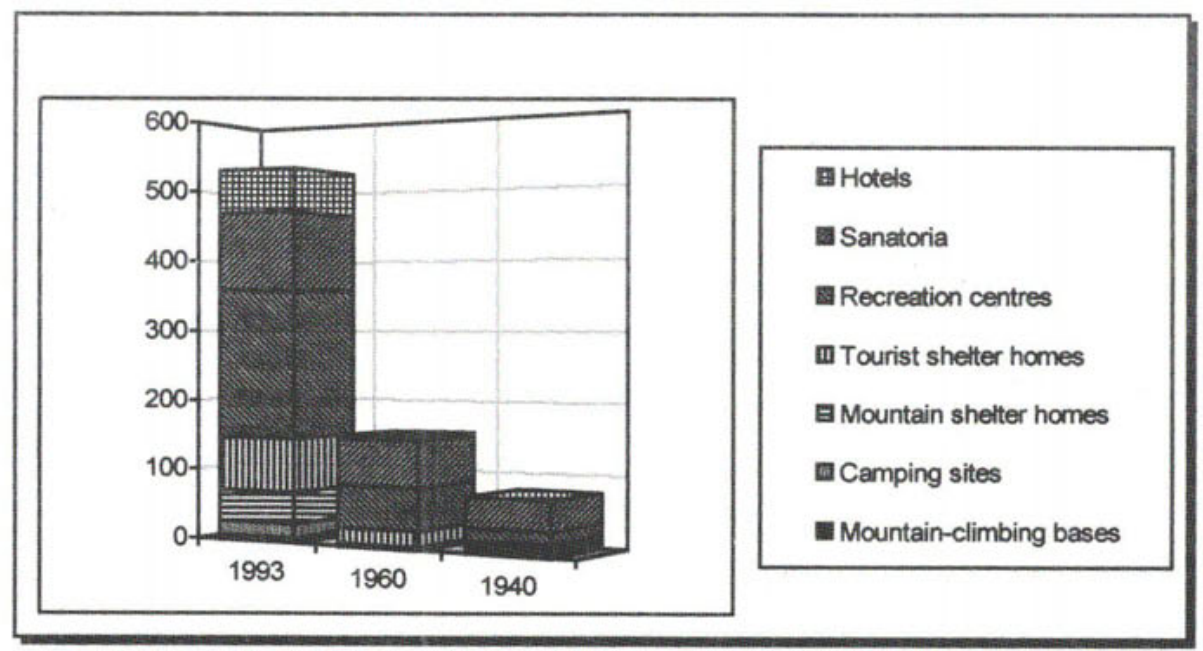

Fig. 1. Accommodation base of Western Caucasus

centres and sanatoria, which confirms the recreational and therapeutic character of tourism in this area. However, during the last 25 years an increasingly significant role has been played by mountain tourism. This can be seen in an increase in the number of tourist shelter-homes and mountain shelter-homes. 
The structure of accommodation base of Western Caucasus

\begin{tabular}{|l|r|r|r|}
\hline & 1940 & 1960 & 1993 \\
\hline Hotels & 0 & 5 & 61 \\
Sanatoria & 41 & 64 & 109 \\
Recreation centres & 18 & 59 & 211 \\
Tourist shelter homes & 6 & 22 & 76 \\
Mountain shelter homes & 0 & 0 & 44 \\
Camping sites & 0 & 1 & 20 \\
Mountain-climbing bases & 11 & 3 & 7 \\
Camping sites & 0 & 1 & 20 \\
Mountain-climbing bases & 11 & 3 & 7 \\
\hline Totals & 76 & 154 & 528 \\
\hline
\end{tabular}

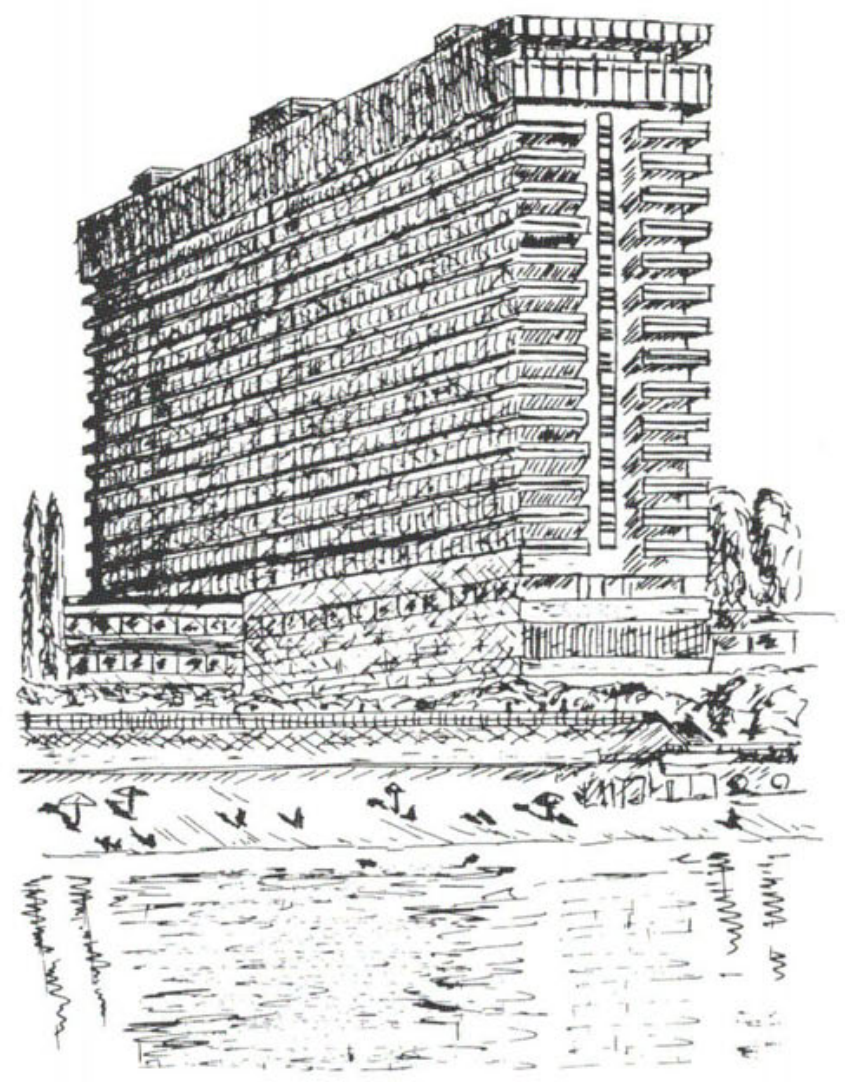

Fig. 2. The "Zhemchushina ${ }^{n}$ hotel in Sochi

Hotels in Western Caucasus are multi-storey buildings. On the average each of them can accommodate from 800 to 1000 guests. The largest object 
of this type is the international ${ }_{n}$ Dagomys" hotel, situated in the town bearing the same name, which can provide lodging for 2500 guests at a time. The smallest number of places to offer (220) has the "Caucasus" hotel in Sochi. These are all-year running objects.

Until 1960 five hotels had been built (not counting the non-existent private hotels built before the October Revolution). In 1993 there were already 61 hotels, which means an over 12-fold increase. The hotels have appeared mostly in large holiday resorts at the seaside (Sochi, Gelendzhik). 62 per cent of the hotels is localized in the seaside zone. Single hotels have been built in other towns. 67 per cent of the hotels is situated in the valleys (of which only one object is localized directly by the river), and 28 per cent - on the terraces.

A sanatorium is an object in which natural conditions of the area are used for therapeutic and preventive purposes. As a rule the number of

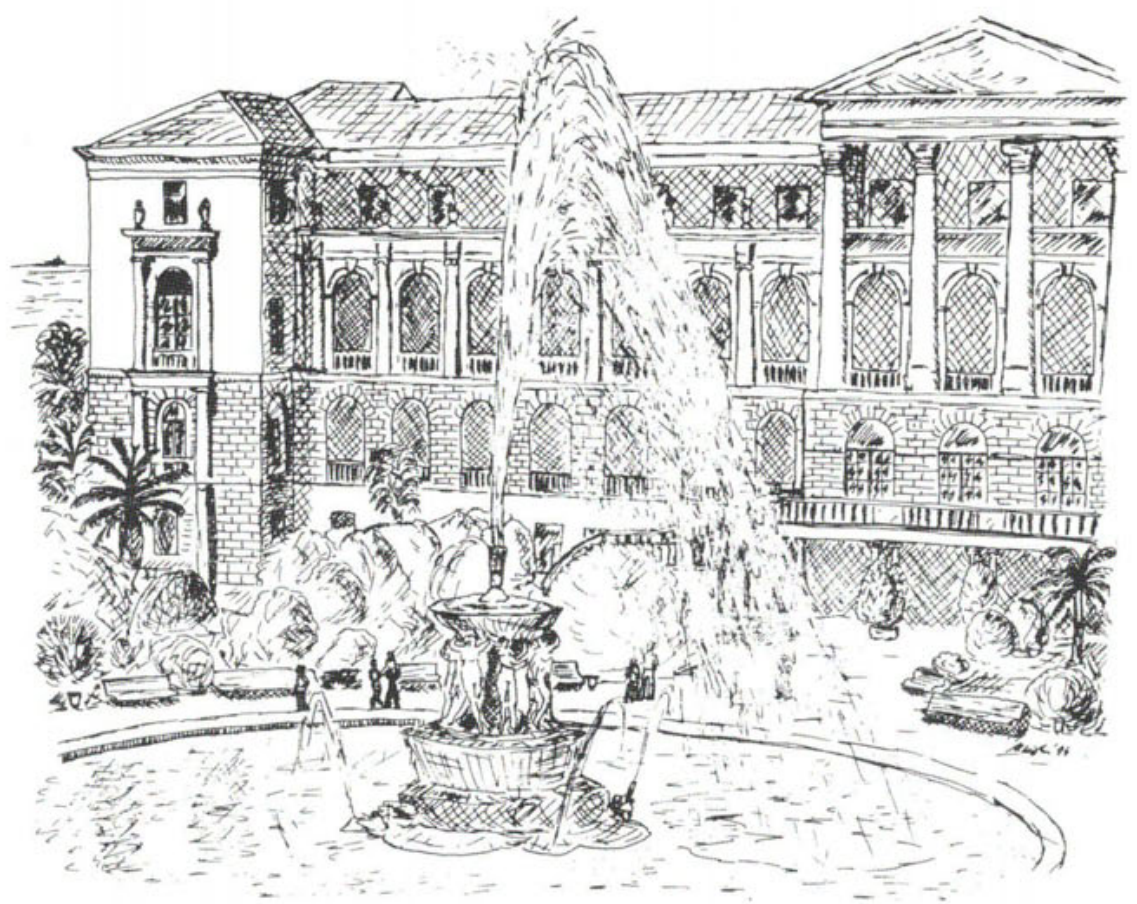

Fig. 3. The Ordzhonikidze sanatorium in Sochi

patients in them drastically diminishes when the summer season is over. The largest is the Kirov sanatorium which can accommodate 1250 people at a time, the smallest one is in Kyepsha (40 people).

In the area of Western Caucasus 109 objects of this type have been built. Most of them are situated in the seaside zone. Before the war 73 per cent of all sanatoria were localized there. After the war, until 1960 new sanatoria were 
built only in the seaside zone and thus their per cent share in the total number of objects of this type increased up to 86 per cent, to decrease slightly to 81 per cent in 1993. Other sanatoria were located in low mountains at the level of leafy forests (all of them in the health resort called Goryachiy Klyuch), and also in medium-high mountains at the level of coniferous forests (all of them in Teberda), the location being connected with the presence of mineral springs in the area. Almost one third of the sanatoria were situated close to mineral springs, which emphasizes their role in the therapeutic form of tourism. As much as 61 per cent of the sanatoria is situated in the zone of subtropical climate, which constitutes a mere 3 per cent of the total area of Western Caucasus. Also the most famous health resort, Sochi, is situated in this zone.

Recreation centres, by which we mean here a group of various therapeutic objects, basically aiming at offering recreation to healthy

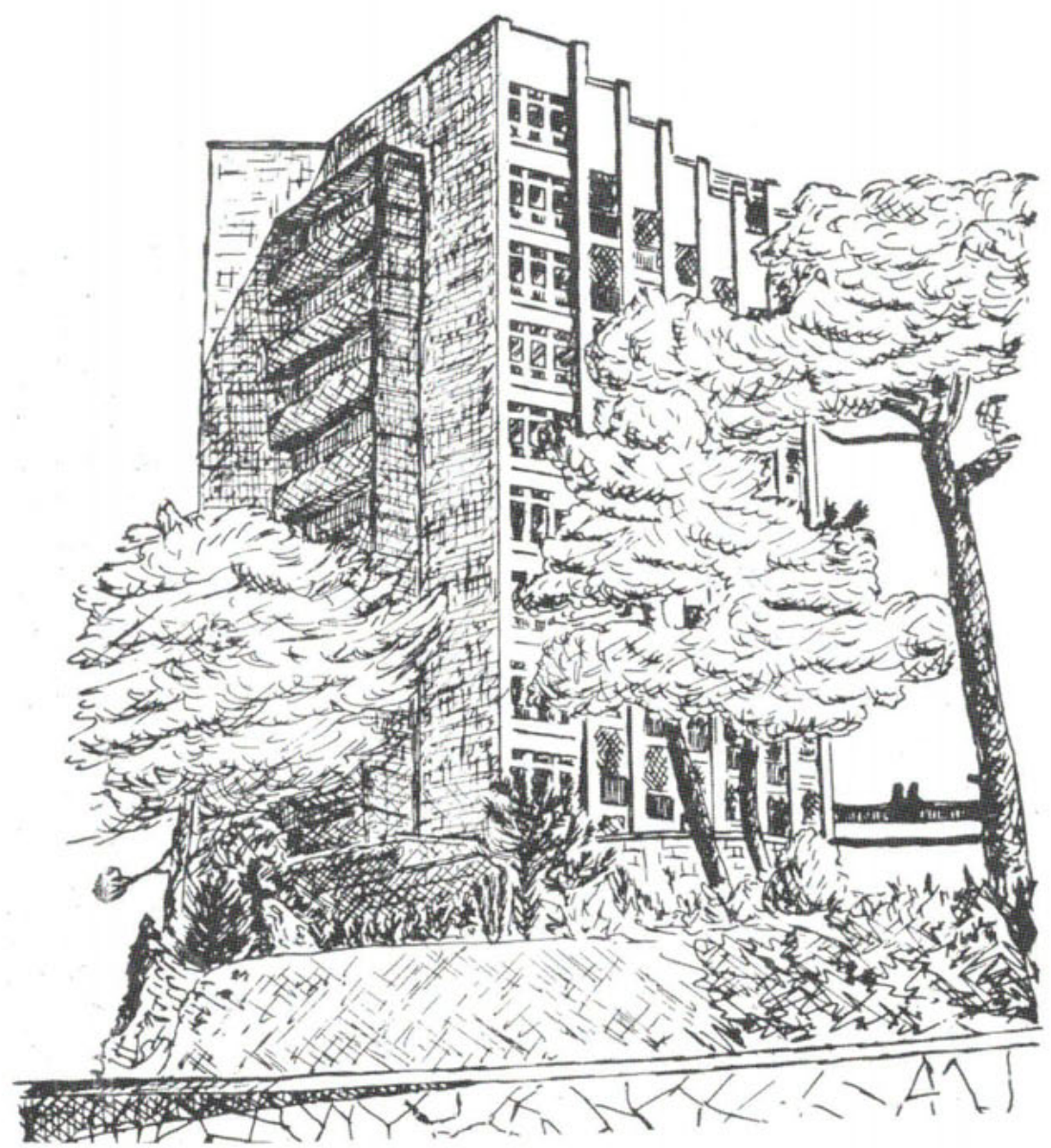

Fig. 4. A recreation centre in Divnomorskoye 
people. They operate all year round, although the number of guests considerably diminishes outside of the summer season. Altogether in 1993 there were 211 objects of this type functioning, whereas in $1960-59$, and in 1940 - only 18 . They appeared mainly in the seaside zone (87 per cent in 1993). It should be emphasized here that their number is increasing. Every fourth object of this type is situated close to mineral springs, only three are located by the rivers. Generally, the per cent share of accommodation bases built at the bottom of valleys decreases, and of those built on the terraces increases.

Tourist shelter homes are situated in hotel-type buildings, and their location is connected with tourist routes of various kinds: hiking routes, waterway routes, skiing routes, riding routes, coach lines, or routes of combined type. These are several storey buildings which can accommodate from 100 to 500 people at a time. In 1993 in Western Caucasus there were 76 tourist shelter homes. At the beginning of the $60 \mathrm{~s}$ - there were 22 , and shortly before the second world war - merely 6 . Tourist shelter homes were mainly localized at the bottom of valleys (67 per cent). Half of them have been localized in the seaside zone, and 16 per cent - by the rivers. Tourist shelter homes were built in the main tourist centres of the area, such as Dombay, Teberda, Arkhyz, Krasnaya Polyana, and also along tourist routes running from the Northern Caucasus Plain to the Black Sea.

Mountain shelter homes mainly serve to provide accommodation for the night only, usually for individual tourists. They lack any sanitary facilities, and usually cannot be reached by car. They are small objects which can provide lodging for 10 to 50 people only. Usually built of wood, very often they happen to be former shepherd huts. In 1993 there were 44 mountain shelter homes in the area. Before 1960 objects of this type did not exist at all.

They were localized in places situated far from human settlements and tourist centres, in the mountainous part of Western Caucasus, chiefly (75 per cent) in medium-high mountains. One can also notice a strong dependence of the location of mountain shelter homes on the water-courses. 73 per cent of them is situated at the bottom of valleys, of which 41 per cent directly by the river. For hikers it is not so much important that the accommodation base be situated near a road; they even do not mind when the access to such a base is actually rather difficult. They are much more interested in the beauty of natural environment which will make up for the difficulties connected with reaching the place.

Camping sites are typical seasonal objects, destined for motorists travelling with a tent or a caravan. Until 199320 camping sites were created. In 1960 there was only one object of this type, and earlier there were none at all. The majority of the camping sites (85 per cent) are situated at the seaside. The remaining ones are localized in plateaux, not far from big towns. 65 per cent of them was localized at the bottom of valleys, whereas 33 per cent - on the terraces; such localization was neces- 


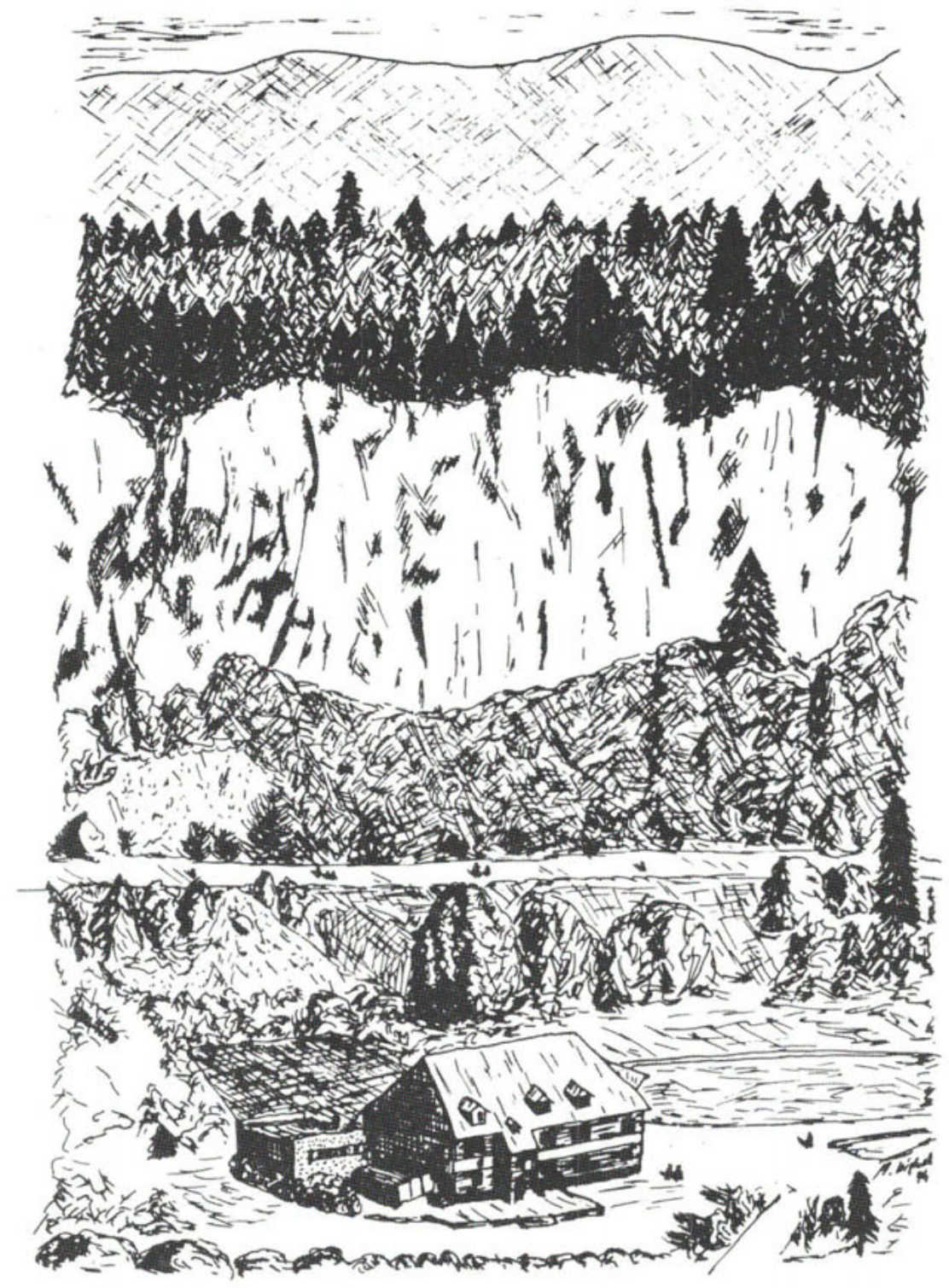

Fig. 5. A tourist shelter home. Lago-Naki

sary to ensure easy access to the objects. Every fourth object is localized by the river, and every third one - close to mineral springs.

Last but not least, we ought to mention mountain-climbing bases. There are 7 such bases in Western Caucasus, which makes 35 per cent of all mountain-climbing bases situated on the territory of the Commonwealth 
of Independent States. In 1960 there were 3 such bases, and in $1940-11$ (almost all bases in the former USSR).

Before the war all of them were localized on the Dombayskaya Polyana. As a matter of fact, in 1993 out of the total number of seven mountain-

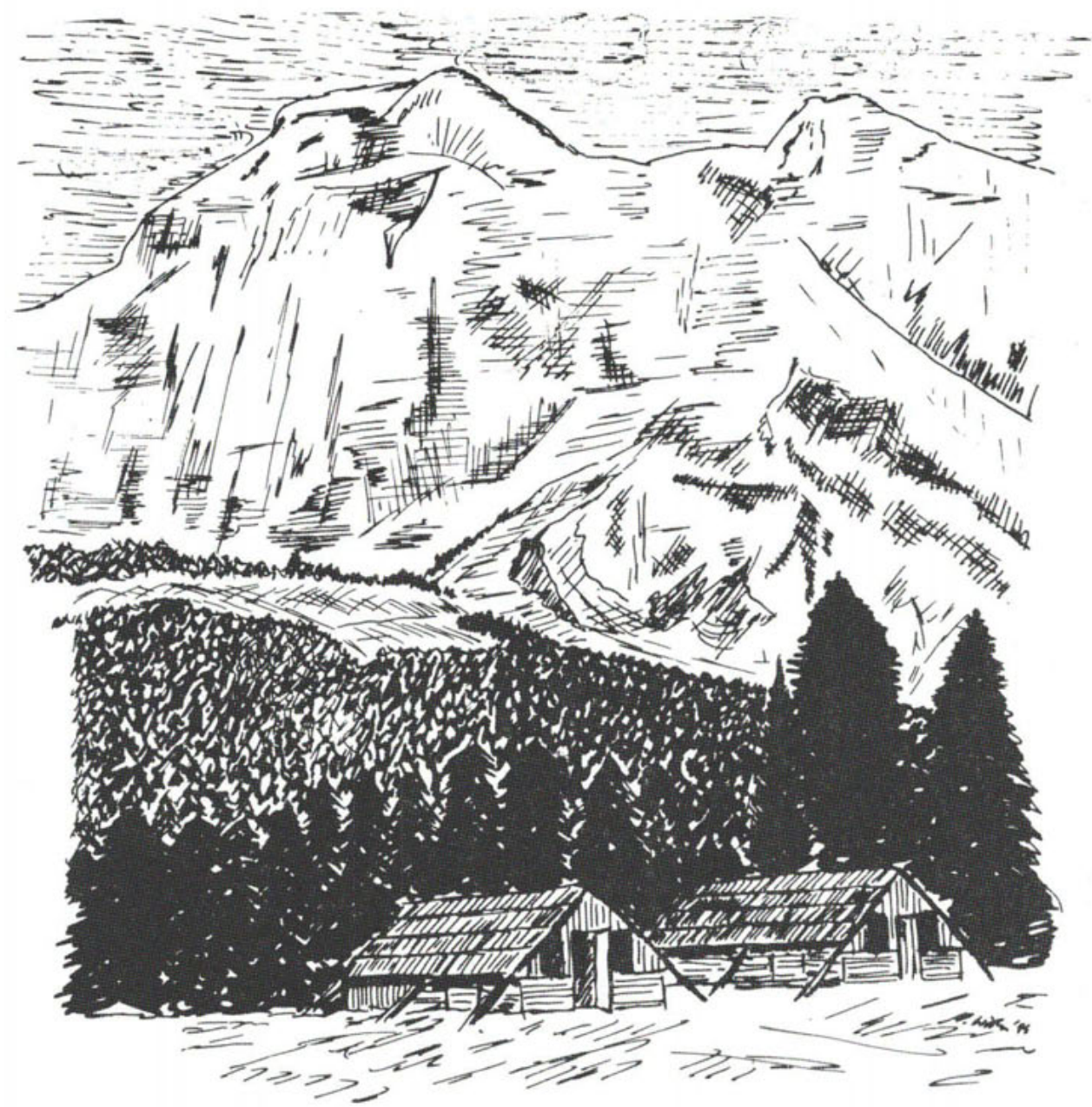

Fig. 6. A mountain shelter home at the foot of mount Fisht

climbing bases as many as six were situated there. This was because every climbing club had the ambition to open its base precisely in this site.

The mean density of occurrence of accommodation bases in Western Caucasus is 14.6 objects per $1000 \mathrm{~km}^{2}$. Their distribution varies considerably. They are mostly concentrated along the coast of the Black Sea. In the seaside zone which stretches between the coast line and the culmination of 
the first hills, covering the area of some $877 \mathrm{~km}^{2}$, there are 364 objects (almost 70 per cent of the total accommodation base of Western Caucasus). Their density in this area is equal to 415.1 objects per $1000 \mathrm{~km}^{2}$, a value which exceeds almost 28 -fold the average. They are concentrated at the seaside, and practically never appear (except very rarely, for instance when a new health resort is being created) outside of tourist centres. There are several important reasons for such high concentration of accommodation objects in the seaside zone, namely:

- great attractiveness of the coast which has been classified as the most attractive in Russia, and second only to the Abkhasian part of the former USSR - warm sea, mild climate, long summer (with water temperatures of over $+17^{\circ} \mathrm{C}$ and air temperatures of over $+20^{\circ} \mathrm{C}$ ), lasting from 110 days in the north-western part of the Caucasus coast at the Black Sea to 150 days in its south-eastern part, high insolation ranging from 2100 to 2500 hours in a year, picturesque coast (combination of seaside and mountainous landscape), exotic, subtropical and mediterranean vegetation;

- predominance of recreational and therapeutic forms of tourism over other forms of spending leisure time;

- relatively short distance and easy access to the coast;

- more difficulties connected with building tourist infrastructure in the mountains;

- until the 60s-70s, small popularity of mountain tourism, winter sports and climbing (also because these forms of tourism were treated as privileged ones) and thus no necessity to build tourist infrastructure in the mountains.

After 1960 there was a sudden development of tourist infrastructure in the mountainous part of the area, where in the last thirty years the number of objects of accommodation base has increased almost fivefold. This was due to a number of factors, among them:

- general growth of interest in the mountains;

- perceiving the highly differentiated natural environment of the mountains as obviously advantageous for the development of tourism;

- attractiveness of practising tourism all year round and increasing popularity of practising different forms of tourism - greater possibilities of making use of qualified tourism;

- growing popularity of winter sports among the general public;

- a chance of escape from urban tumult;

- increasing overcrowding of the seaside zone.

Unlike the accommodation bases at the seaside, the objects situated in the mountains are more dispersed, which gives the tourists an opportunity to walk from one to another. Some larger tourist centres in the mountainous part of the region appeared before the second world war. Later, however, they developed to a very small extent only. We should mention here Dombay and Krasnaya Polyana as climbing and skiing centres, and 
also Teberda and Goryachiy Klyuch - the centres of therapeutic and recreational tourism. After 1970 attempts were made to find new sites for localization of accommodation base, so as not to overload the sensitive natural environment of the mountains.

The localization of the objects of accommodation base in Western Caucasus was noticeably affected by orography.

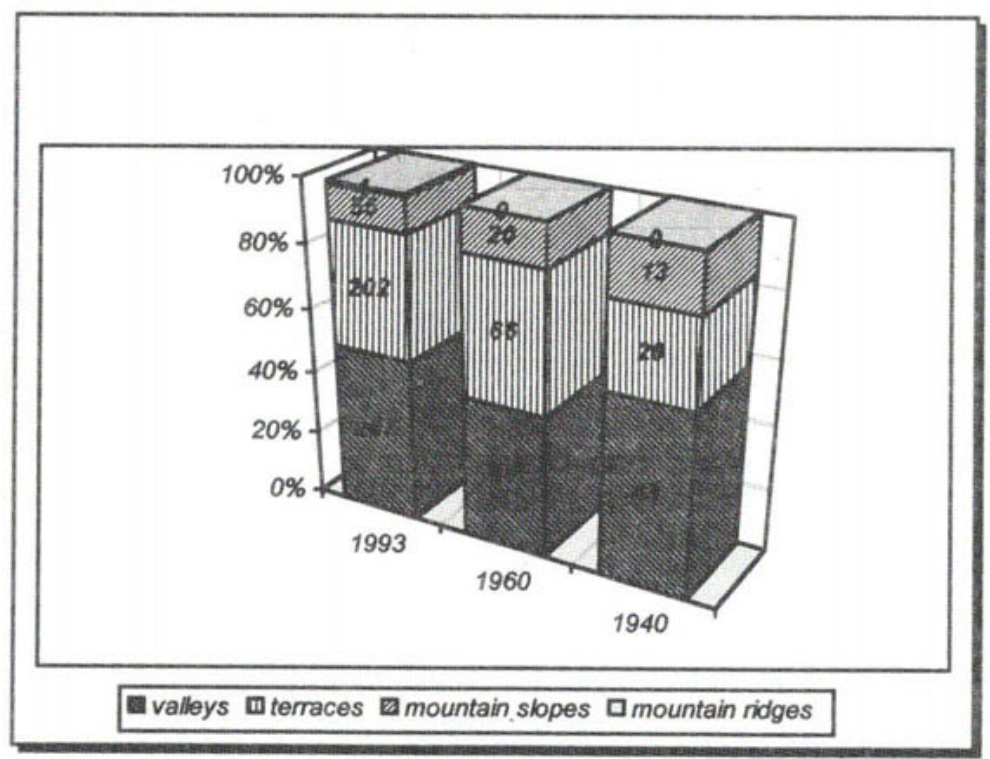

Fig. 7. The objects of accommodation base in different types of relief

In 1993 the majority of the objects were situated at the bottom of valleys, where 50.6 per cent of accommodation base was concentrated. In comparison with mountain slopes or ridges, the valleys are characterized by large areas of flat land, with only mild slopes, and thus they can be easily reached. Moreover, they have milder climate and easier access to water. The closer one gets to the Central Caucasus Ridge the more dismembered the relief becomes. The slopes are steeper and denivelations increase. In most cases the relief stipulates the localization of tourist objects. The sites chosen for construction of such objects are usually situated in places where two or more valleys meet. The flat area in such a place is much larger than that at the bottom of one valley only, and the site is more distant from mountain slopes, which means there is lesser threat of avalanches. The tourist settlements of Dombay, Teberda, Arkhyz, Krasnaya Polyana, and also some individual objects, were created in precisely such places.

38.3 per cent of accommodation base of Western Caucasus is situated on seaside terraces. The inclination of these areas is much smaller than that of 
mountain slopes, they can be easily reached and are lying in direct neighbourhood of the sea.

The localization of accommodation base, and also its structure, are strongly influenced by natural environment (in the broad meaning of the term) in which certain types can be distinguished (see Table 2 and Fig. 8).

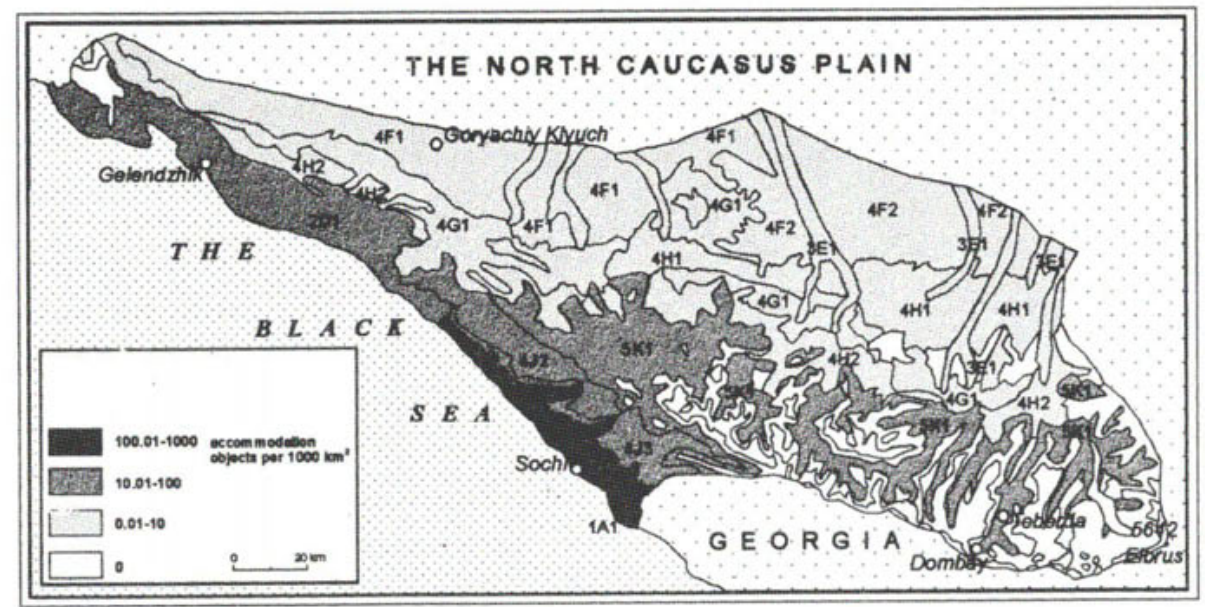

Fig. 8. Types of landscape in Western Caucasus against tourist management in 1993

In 1940 the majority of the objects of accommodation base were localized at the seaside, with subtropical or mediterranean climate. In the landscapes of temperate climate, characterized by flat, hummocky, or karstic relief, all the objects were localized close to mineral springs. In the landscape of mediumhigh mountains, close to high mountains, two big tourist centres appeared: Teberda and Dombay. At the seaside the majority of objects were built on the terraces, whereas in the mountains - in valleys.

Until 1960 new tourist objects were built in the same landscapes as before. There was no change in the development of tourism in this respect. The preferred landscapes were still those at the seaside, whereas in plateaux and karstic landscapes close vicinity of mineral springs was a fundamental criterion of choice, as they were used for therapeutic purposes. The only exception here is the landscape of medium-high mountains (5K1), where the tourist objects which had been destroyed during the war, were not reconstructed. This was mainly because this part of the Caucasus is particularly difficult to reach, and also due to clear preferences of the seaside zone.

In 1993 the landscapes characterized by subtropical climate (1A1 and 1B1) are among the best developed areas of Western Caucasus. One should emphasize here the occurrence of luxuriant tropical vegetation and diversified relief. The landscapes of mediterranean climate in medium-high mountains (2D1) are also characterized by a large density of tourist objects. 


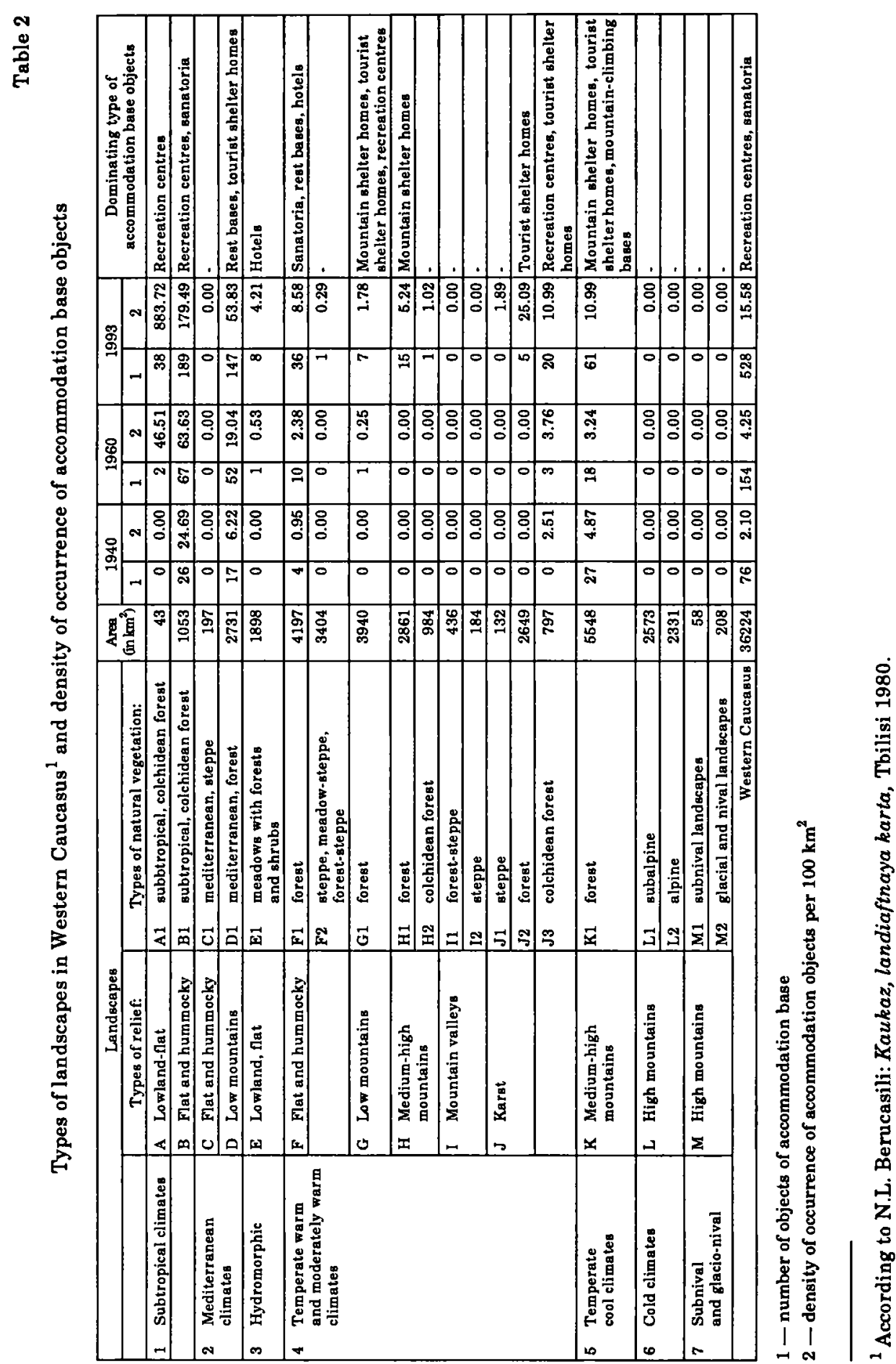


In addition, it can be noticed that the centre of gravity of tourist management is turning towards the mountains. The largest number of accommodation objects out of those not situated at the seaside have been localized in the areas of temperate cool climate, in medium-high mountains. This is caused by highly attractive natural conditions of those areas, first of all diversified relief and rich coniferous forests (mainly spruce and fir). These areas are bordering high mountains which attract the growing number of tourists. From the above-mentioned forests there is one step only to luxuriant subalpine meadows, multicoloured alpine meadows, blue lakes, glaciers and majestic peaks. It should be noted here that this is where all tourist routes crossing the Central Caucasus Ridge meet. However, in the high mountains there are no accommodation objects. Above the upper forest border begins the destructive activity of mass movements, such as avalanches or landslides, the climate is very cold (especially in winter: low temperatures, heavy snowfalls, strong winds) and there are hardly any flat areas suitable for building. That is why the accommodation objects have been localized in the forest range, in many cases close to the upper forest border. Such location is safe enough and favourable for various forms of mountain tourism, such as climbing or skiing.

Most of the objects of accommodation base are concentrated in the forests of different types: colchidean, mediterranean, leafy mountain forests and coniferous mountain forests. In subtropical forests the accommodation objects are concentrated at the seaside at the border line of the forests and the coast. In mediterranean forests the situation is similar. As far as mountain forests are concerned, and in particular in medium-high mountains, the majority of objects are localized on clearings. Such locations make it possible for the tourists to admire the beauty of the mountains (the trees do not obstruct the view), there is a high amount of oxygen and essential oils in the air, and the forest provides protection against avalanches and other mass movements, as well as against strong winds.

Summing up, it can be said that in Western Caucasus the objects of accommodation base are mainly concentrated in the seaside zone. However, one can notice the growing role of the mountains as new areas preferred for localization of such base. The rich natural environment of high mountains attracts the tourists, but also creates considerable obstacles for localization of accommodation objects. Such barriers, difficult to overcome, are the extreme environment of high mountains and the relief. In the seaside zone the recrealional and therapeutic forms of tourism dominate, and therefore the main objects localized there are recreation centres and sanatoria. In the mountains, because of a different form of tourism practised there, tourist shelter homes and mountain shelter homes developed.

It should be noted that the structure and distribution of the objects of accommodation base in Western Caucasus were affected by such factors as the diversified landscape, and also the sea, types of relief, forests and mineral springs. 